\title{
Determining the numbers of a landscape architect species (Tapirus terrestris), using footprints
}

\author{
Danielle O Moreira ${ }^{\text {Corresp., }}$ 1, 2, 3 , Sky K Alibhai ${ }^{1,4}$ ，Zoe C Jewell ${ }^{1,4}$ ， Cristina J da Cunha ${ }^{3}$, Jardel B Seibert ${ }^{2,3}$, \\ Andressa Gatti ${ }^{2,3}$ \\ 1 Nicholas School of the Environment, Duke University, Durham, North Carolina, United States of America \\ 2 Programa de Pós-graduação em Ciências Biológicas (Biologia Animal), Departamento de Ciências Biológicas, Universidade Federal do Espírito Santo, \\ Vitória, Espírito Santo, Brazil \\ 3 Pró-Tapir, Instituto de Ensino, Pesquisa e Preservação Ambiental Marcos Daniel (IMD), Vitória, Espírito Santo, Brazil \\ 4 JMP Division, SAS, Cary, North Carolina, United States of America \\ Corresponding Author: Danielle O Moreira \\ Email address: daniomoreira@gmail.com
}

Background. As a landscape architect and a major seed disperser, the lowland tapir (Tapirus terrestris) is an important indicator of the ecological health of certain habitats. Therefore, reliable data regarding tapir populations are fundamental in understanding ecosystem dynamics, including those associated with the Atlantic Forest in Brazil. Currently, many population monitoring studies use invasive tagging with VHF or satellite/GPS collars. These techniques can be costly and unreliable, and the immobilization required carries physiological risks that are undesirable particularly for threatened and elusive species such as the lowland tapir.

Methods. We collected data from one of the last regions with a viable population of lowland tapir in the south-eastern Atlantic Forest, Brazil, using a new non-invasive method for identifying species, the Footprint Identification Technique (FIT).

Results. We identified the minimum number of tapirs in the study area and, in addition, we observed that they have overlapping ranges. Four hundred and forty footprints from 46 trails collected from six locations in the study area in a landscape known to contain tapir were analyzed, and 29 individuals were identified from these footprints.

Discussion. We demonstrate a practical application of FIT for lowland tapir censusing. Our study shows that FIT is an effective method for the identification of individuals of a threatened species, even when they lack visible natural markings on their bodies. FIT offers several benefits over other methods, especially for tapir management. As a non-invasive method, it can be used to census or monitor species, giving rapid feedback to managers of protected areas. 
1 Determining the numbers of a landscape architect species (Tapirus terrestris), using

2 footprints

3

4 Danielle O. Moreira*1, 2,3, Sky K. Alibhai ${ }^{1,4}$, Zoe C. Jewell ${ }^{1,4}$, Cristina J. da Cunha ${ }^{3}$, Jardel

5 B. Seibert ${ }^{2,3}$, Andressa Gatti ${ }^{2,3}$

$6{ }^{1}$ Nicholas School of the Environment, Duke University, Durham, North Carolina, United States

7 of America.

$8{ }^{2}$ Programa de Pós-graduação em Ciências Biológicas (Biologia Animal), Departamento de

9 Ciências Biológicas, Universidade Federal do Espírito Santo, Vitória, Espírito Santo, Brazil.

$10{ }^{3}$ Pró-Tapir, Instituto de Ensino, Pesquisa e Preservação Ambiental Marcos Daniel

11 (IMD), Vitória, Espírito Santo, Brazil.

$12{ }^{4}$ JMP Division, SAS, Cary, North Carolina, United States of America.

$14 *$ Corresponding author.

15 Danielle Moreira

16 E-mail address: daniomoreira@gmail.com

Abstract

Background. As a landscape architect and a major seed disperser, the lowland tapir (Tapirus terrestris) is an important indicator of the ecological health of certain habitats. Therefore,

21 reliable data regarding tapir populations are fundamental in understanding ecosystem dynamics,

22 including those associated with the Atlantic Forest in Brazil. Currently, many population

23 monitoring studies use invasive tagging with VHF or satellite/GPS collars. These techniques can 
24 be costly and unreliable, and the immobilization required carries physiological risks that are

25 undesirable particularly for threatened and elusive species such as the lowland tapir.

26 Methods. We collected data from one of the last regions with a viable population of lowland

27 tapir in the south-eastern Atlantic Forest, Brazil, using a new non-invasive method for

28 identifying species, the Footprint Identification Technique (FIT).

29 Results. We identified the minimum number of tapirs in the study area and, in addition, we 30 observed that they have overlapping ranges. Four hundred and forty footprints from 46 trails

31 collected from six locations in the study area in a landscape known to contain tapir were

32 analyzed, and 29 individuals were identified from these footprints.

33 Discussion. We demonstrate a practical application of FIT for lowland tapir censusing. Our

34 study shows that FIT is an effective method for the identification of individuals of a threatened

35 species, even when they lack visible natural markings on their bodies. FIT offers several benefits

36 over other methods, especially for tapir management. As a non-invasive method, it can be used

37 to census or monitor species, giving rapid feedback to managers of protected areas. 


\section{Introduction}

One of the key ecological processes that maintain the health status of tropical forests is seed dispersal (Boissier et al. 2014). Vertebrates can disperse between $45 \%$ and $90 \%$ of woody species seeds and mammals are important dispersers in warmer forests (Almeida-Neto et al. 2008). The lowland tapir, Tapirus terrestris (Linnaeus, 1758), a remaining species of the Pleistocene megafauna in South and Central America (Simpson 1980; Eisenberg 1981), is a large selective browser (180-300 kg), and an important vertebrate seed disperser because it can disperse large-seeded species over long-distances (Dirzo \& Miranda 1991; Galetti et al. 2001; O'Farrill et al. 2012; Bueno et al. 2013).

In Brazil, lowland tapir populations are decreasing at an alarming rate due to habitat destruction and fragmentation, illegal fires (Chiarello 2000a; Michalski \& Peres 2007), hunting (Chiarello 2000b; Peres 2000) and road kill (Medici \& Desbiez 2012; Souza et al. 2015), especially in the Atlantic Forest and Cerrado ecosystems. Consequently, the lowland tapir is listed as Vulnerable in the IUCN Red List of Threatened Species (Naveda et al. 2008), and in the Brazilian list of Threatened Species (Instituto Chico Mendes de Conservação da Biodiversidade 2016). In the Atlantic Forest, tapirs are considered as Endangered (Medici et al. 2012).

The disappearance of frugivores such as tapirs from disturbed tropical forests can reduce the recruitment and survival of plant species, threatening forest regeneration (Boissier et al. 2014). Thus, tapirs can be considered a landscape architect and a major indicator of ecological health of landscapes (Bueno et al. 2013; O'Farrill et al. 2013; Giombini et al. 2016). Understanding tapir population dynamics is therefore crucial to the health of Brazilian Atlantic Forest ecosystems.

Gatti et al. (2011) and Medici \& Desbiez (2012) estimated that a lowland tapir population 
62 is considered genetically stable in the Atlantic Forest if it consists of at least 200 animals at all

63 times over a 100-year period. However, only three areas currently have a population of more

64 than 200 individuals in the Atlantic Forest (Medici et al. 2012), the Serra do Mar forest complex,

65 the State Park of Rio Doce and the Linhares/Sooretama forest complex. If no conservation

66 intervention is taken to protect the species in the Atlantic Forest, it is predicted that the

67 remaining populations will disappear in 33 years (Medici et al. 2012). Without reliable

68 information on demographics, developing a strategy for sustaining free-ranging tapir populations

69 will be impossible (Foerster \& Vaughan 2002). However, while lowland tapir population

70 censusing and monitoring is essential, it is a difficult task because tapir are mostly crepuscular

71 and nocturnal (Oliveira-Santos et al. 2010; Wallace et al. 2012; Cruz et al. 2014).

72 Classical studies of tapir population censusing and monitoring include individual

73 counting by direct sightings (Fragoso 1987; Glanz 1990), scat surveys (Naranjo \& Cruz 1998;

74 Flesher 1999; Ramírez 2013), footprint counts (Naranjo \& Cruz 1998; Flesher 1999; Naranjo \&

75 Bodmer 2007), line transect sampling (Naranjo \& Cruz 1998; Naranjo \& Bodmer 2007; Medici

76 2010; Wallace et al. 2012), the use of high technology such as camera traps (Wallace et al. 2012;

77 Carbal-Borges et al. 2014; Mejía-Correa et al. 2014; Tobler et al. 2014) and VHF/GPS collars

78 (Foerster \& Vaughan 2002; Medici 2010). However, the research costs and duration have often

79 hampered the implementation of these methods. Nevertheless, many facets of wildlife research

80 demand the recognition of individual animals (Alibhai et al. 2008). For tapirs, each of these

81 methods has disadvantages. For example, adult tapirs do not have natural coat patterns that can

82 easily distinguish an individual during a census or in a camera trap image and to fit a tag or

83 radio-collar, it is necessary to capture and immobilize a tapir, which comes with ongoing

84 expenses and risks to animal and researcher. 
A new cost-effective and non-invasive method for identifying endangered species is the

86 Footprint Identification Technique (FIT) (Alibhai et al. 2008; Jewell \& Alibhai 2013; Jewell et

87 al. 2016; Alibhai et al. 2017), which is capable of identifying at the individual, sex and age-class

88 levels from digital images of footprints of certain species. It is considered a cost-effective

89 method because of the low investment for fieldwork combined with high accuracy in individual

90 identification (Gusset \& Burgener 2005; Jewell 2013; Pimm et al. 2015; Jewell et al. 2016). In

91 this way, footprints can serve as an alternative to natural coat patterns or body marks for those

92 species whose foot is of sufficient complexity to create a footprint with individual characteristics.

93 The technique proved to be effective with footprints of black rhino (Diceros bicornis) (Jewell \&

94 Alibhai 2001) and white rhino (Ceratotherium simium) (Alibhai et al. 2008). FIT has

95 subsequently been adapted for several other species, including Amur tiger (Panthera tigris ssp.

96 altaica) (Gu et al. 2014), cougar (Puma concolor) (Jewell et al. 2014; Alibhai et al. 2017), brown

97 bear (Ursus arctos) (Petridou et al. 2008), cheetah (Acinonyx jubatus) (Jewell et al. 2016), panda

98 (Ailuropoda melanoleuca) (Li et al. 2018), Bengal tiger (Panthera tigris ssp. tigris), polar bear

99 (Ursus maritimus) and Baird's tapir (Tapirus bairdii) (Jewell \& Alibhai 2013). In 2007, the

100 method was tested for the first time for the lowland tapir in the Atlantic Forest (Medici 2010).

101 This study is an attempt to census one of the last regions with a viable population of

102 tapirs in the southeastern Atlantic Forest - the Linhares-Sooretama forest complex in the state of

103 Espírito Santo, Brazil. This population survives in a forested area of about 50,000 ha. FIT

104 methodology has the potential to census tapir populations and help implement species

105 management and conservation strategies, especially for disturbed tropical ecosystems dependent

106 on frugivores for maintenance. Thus, determining tapir distribution and numbers accurately is a

107 major challenge for tropical ecologists. 
109 Material \& Methods

110 Study area

111 We performed the study in the Private Natural Heritage Reserve Recanto das Antas

112 (Reserva Particular do Patrimônio Natural Recanto das Antas, in Portuguese, hereafter

113 "RPPNRA") and adjacent private areas to the reserve (Fig. 1). The RPPNRA is a private

114 protected area of 2,212 hectares owned by Fibria Celulose S.A., a Brazilian company, located in

115 the Linhares-Sooretama forest complex, north of the state of Espírito Santo, Brazil. It is

116 contiguous with the 27,858 ha Sooretama Biological Reserve and the 22,711 ha Vale Natural

117 Reserve. The RPPNRA is located at the coordinates $19^{\circ} 5^{\prime}$ south latitude, $39^{\circ} 58^{\prime}$ west longitude,

118 and mostly consists of discontinuous primary vegetation, interposed by extensive eucalyptus and 119 papaya plantations, cabruca (cacao trees planted in the shade of thinned native forest), seringal

120 (rubber tree culture) and smaller amounts of coffee plantations and cattle pastures, which are not 121 part of the reserve (Centoducatte et al. 2011). Unpaved roads used for eucalyptus harvesting and 122 transportation also cross the area.

123 The study site is situated in an area of Barreiras Formation (Tertiary sediments, or 124 "tabuleiros"), where the vegetation is part of the Ombrophilous Forest Region of the Lowlands 125 (Instituto Brasileiro de Geografia e Estatística 1987), also known as the Tabuleiros Atlantic 126 Forest (Rizzini 1997). The Tabuleiros Forest of Linhares and Sooretama region is considered of 127 high biological importance for the conservation of the biodiversity (Conservação Internacional 128 do Brasil et al. 2000), a priority area for the conservation of medium- and large-sized mammals 129 (Galetti et al. 2009) and part of the UNESCO World Heritage Discovery Coast Atlantic Forest 130 Reserves. 
132 Collection of footprints

133 The lowland tapir, an ungulate from the order Perissodactyla, whose toes are surrounded

134 by a hoof, has four digits on the forefeet, representing anatomical digits 2, 3, 4 and 5 . The

135 smallest one (the fifth digit) appears only in footprints impressed in soft ground (Ballenger \&

136 Myers 2001). The hind feet have only three digits (anatomical digits 2, 3, and 4), and they each

137 appear in the footprint (Medici 2011). Tapirs, like many terrestrial large mammals, typically

138 register the hind foot in the impression left by the front foot when they are walking (Jewell \&

139 Alibhai 2001; Elbroch 2003; Alibhai et al. 2008; Jewell et al. 2016).

140

Footprint surveys were performed on 17 dirt (unpaved, soft surface) roads, which

141 represent the main dirt roads crossing the study area. The total length of surveyed roads was

14235,118 meters. One road was visited at least once in each field survey. We chose dirt roads

143 because (1) tapirs use them frequently, (2) the roads cross many different types of habitat,

144 including forest and agriculture land, and (3) we had easy access to them. Because lowland tapirs

145 are active mostly between dusk and dawn (Oliveira-Santos et al. 2010; Wallace et al. 2012; Cruz

146 et al. 2014), our surveys were done early in the morning and in the late afternoon, when there

147 was sufficient light for photography. The availability of footprints of tapirs on roads also

148 depended to some extent on the weather. The quality of footprints was sometimes reduced when

149 the weather was too dry because footprint impressions were not held so well by the substrate,

150 and when it rained footprints were lost. The footprint identification technique requires well-

151 defined clear footprints, generally obtained from animals walking at a relaxed pace so we used

152 only undistorted footprints in this study.

153 We collected sets of digital images of footprints from wild lowland tapirs, as follows, 
154 following the WildTrack FIT protocol (Alibhai et al. 2008; Jewell et al. 2016). First, we

155 identified a trail (an unbroken series of footprints made by the same animal) of footprints left by

156 an individual (Fig. 2A). Left hind footprints were used for the analysis following the protocol

157 given in Alibhai et al. (2008). For each footprint image, a scale (in centimeters) was placed to the

158 left and bottom of it, and a slip was placed alongside one of the rulers with the date, name of the

159 road, UTM coordinates, collector and footprint code (Fig. 2B). Each day, every trail and

160 footprint received a unique code. Photographs were taken at high resolution (2248 X 4000 pixels

161 or higher), from directly overhead (although FIT can work quite effectively at 1600 X 1200).

162 To avoid the risk of collecting a footprint more than once, we obliterated each footprint

163 after taking the photos. We carried out ten fieldwork sessions of three to five days duration

164 during 10 months between March 2014 and June of 2015 in the study area. To enable a more

165 detailed analysis of the minimum number of tapirs in the area, we arbitrarily divided the study

166 area into six locations based on distribution of footprint trails (A-F; Fig. 1). The subdivision of

167 locations allowed a comparison of the number of trails and the number of animals in different

168 areas. Maps were designed in ArcMap 10.1 (®Esri). The farthest distance between two areas was

169 6,297 meters (area C and E), the smallest distance was 1,110 meters (area A and B), while the 170 average distance among the areas was 3,290 meters (Table 1).

171 We received permission to conduct fieldwork in our study area from SISBIO/Instituto

172 Chico Mendes de Conservação da Biodiversidade (number 32565-5), according to the Brazilian 173 laws.

174

175 Analysis

176 The identification of individuals using FIT is based on the morphometrics of the footprint 
177 (Alibhai et al. 2001; Alibhai et al. 2008; Jewell et al. 2016; Alibhai et al. 2017). Because each

178 species has a unique foot anatomy, FIT algorithms are designed to be species specific. Each

179 species FIT algorithm defines the footprint measurements that allow the software to discriminate

180 between individuals for that species (Alibhai et al. 2017). The lowland tapir algorithm was

181 developed by S.K. Alibhai and Z.C. Jewell (Document S1, Document S2) and Medici (2010)

182 through the collection of a training-set database of footprint photographs from known individual 183 captive tapir (Table S1). Randomized holdback trials using the FIT algorithm with the training

184 set gave accuracies of $90 \%$ for the predicted number of individuals (for more details about the

185 FIT algorithm, see Jewell et al. (2016) and Alibhai et al. (2017)). The FIT software home-page,

186 feature extraction page and footprint variable extraction are shown in Fig. 3A, B. The training-

187 set library of 426 images from 36 captive individuals was used to extract the algorithm for

188 individual identification of tapirs using FIT (Alibhai et al. 2001; Alibhai et al. 2008; Medici

189 2010; Jewell et al. 2016; Alibhai et al. 2017). To census the unknown tapir population in this

190 study, we then applied this previously-derived algorithm to the analysis of new footprint images

191 collected from our study area.

192 Prior to the statistical analysis, we uploaded each footprint image into Gimp 2.8.14

193 software to optimize color contrast and crop the images. Each image was then rotated to a

194 standardized orientation using the FIT add-in in JMP Pro 12 (SAS). Fifteen anatomically-based

195 landmark points on a tapir footprint were prior chosen that could be repeated in other studies and

196 clearly identified (Alibhai et al. 2008; Jewell et al. 2016). Using FIT software, these landmark

197 points were then manually placed on each footprint image using cross-hair guidelines to

198 minimize bias (Fig. 3B, C). From these fifteen landmark points, FIT script defined a further set

199 of seven derived points, geometrically constructed from the set of landmarks points (Jewell et al. 
200 2016). From the 15 landmark points and seven derived points, a total of 121 measurements 201 (distances, angles, and areas) were generated for each tapir footprint.

202 This full set of measurements (the 'geometric profile'; Table S2) was taken to include all 203 those that might prove useful in discriminating between footprints (Fig. 3B, C). The set of 204 measurements of all the tapir footprints constituted the dataset upon which all FIT analyses were 205 performed (Alibhai et al. 2008; Jewell et al. 2016). A full step-by-step video account of the 206 footprint identification technique is reported in Jewell et al. (2016). FIT is based on a comparison of sets of footprints (trails) where each trail is an unbroken 208 set of footprints made by one individual. The comparison is made using a customized robust 209 cross-validated pair-wise discriminant analysis. Where trails were composed of more than 10 210 footprints, they were randomly divided into sub-trails each consisting of 5-8 footprints. For 211 example, trail 8214 was divided into three sub-trails arbitrarily - A8214A, A8214B \& A8214C 212 with the prefix (A) denoting the location of the trail in the study area (see Fig. S1), and the 213 suffixes A, B and C represent the three sub-trails (see Jewell \& Alibhai 2001; Alibhai et al. 2008; 214 Jewell et al. 2016). The sub-trails from a single unbroken trail were named 'self' sub-trails for 215 purposes of classification. Sub-trails from different trail sets were named 'non-self' sub-trails. 216 This enabled the comparison of self sub-trails and non-self sub-trails during FIT analysis. For the whole study area (7,900 ha), we analyzed the data at several different scales: (A)

218 We used all the sub-trails to identify the number of individuals in the entire study area (pooled 219 data), (B) we analyzed the data for each location (A-F) separately and we summed that data to 220 identify the number of individuals and (C), we paired the locations and once again compared the 221 pooled data with summed data. Doing so, we were able to identify if one or more tapirs were 222 visiting more than one location. Finally, using the data from the six different locations (A to F), 
223 we tested the relationship between the numbers of trails and tapir population estimates. Images

224 were processed in JMP data visualization software.

225

226 Results

227

We collected a total of 547 footprint images from 48 trails with an average of 11.40

228 footprints per trail, but after discarding some poor quality images we used 440 footprints from 46

229 trails in the analysis (an average of 9.57 footprints per trail). The minimum number of usable

230 footprints in a trail was 4 and maximum was 23. The data were subjected to FIT analysis which

231 generates a cluster dendrogram giving a prediction for the estimated minimum number of

232 individuals and the relationship between sub-trails (Jewell et al. 2016). For the whole study area,

233 FIT gave an estimate of 29 different individuals for pooled data (Fig. 4A, B). We then analyzed

234 the data for each of the six locations and the summed estimate for all six locations was 35

235 individuals. Finally, we compared the pooled and summed estimates for different combinations

236 of locations (Table 2). All pooled estimate values were either equal to or lower than summed

237 values. Location A had the most tapirs identified ( $n=12$; see Fig. S1), whereas locations C and D

238 (see Fig. S2) had only one individual identified (Table 2). Locations A and E combined

239 represented more than $65 \%$ of total individuals identified in the study area (Table 2; Fig S1 and

240 Fig. S3). FIT identified six and seven individuals for the locations B and F, respectively (see Fig.

241 S4 and Fig. S5).

242 The difference between the pooled (29) and summed (35) estimates indicates that six

243 individuals appeared in more than one area during the study period (Table 2). For example, three

244 individual used the closest sites $\mathrm{A}+\mathrm{B}(1,110 \mathrm{~m}$ apart). One individual visited the sites $\mathrm{A}+\mathrm{E}$

245 (1,567 $\mathrm{m}$ apart), three tapirs were recorded visiting the sites $\mathrm{B}+\mathrm{F}(3,868 \mathrm{~m}$ apart) and two 
246 individuals used the sites $\mathrm{A}+\mathrm{F}$ (4,494 m apart). The other sites, when combined, did not indicate

247 any individuals visiting more than one area.

248 Finally, although the data were limited to just six different locations (A to F), we

249 examined the relationship between the number of trails (predictor variable $\mathrm{x}$ ) and the tapir

250 population estimate (response variable y) for each location (Fig.5). The regression was highly

251 significant $\left(\mathrm{y}=1.24+0.62 \mathrm{x}, \mathrm{R}^{2}=0.9660, \mathrm{p}<0.001\right)$.

252

253 Discussion

254

We have demonstrated a practical application of FIT as a means of monitoring the health

of the Atlantic Forest of Brazil, through an assessment of the numbers of an indicator species, the

256

257

258

259

260

261

262

263

264

265

266

267

268

lowland tapir. In the 10 months over which this census was conducted, we identified at least 29

different individuals of lowland tapir in the RPPNRA and surroundings. The study suggested that tapirs in the RPPNRA might have overlapping ranges and that FIT could identify that the some individuals visited more than one location.

Lowland tapirs exhibit extensive home range overlap (Noss et al. 2003; Medici 2010). In our study, we estimated that at least six different individuals shared the same areas. In addition, we found evidence to suggest that they moved long distances within the study area. Lowland tapirs can easily traverse low-quality and non-natural habitats, moving through the landscape matrix in between patches of forest, including eucalyptus and agriculture fields (Noss et al. 2003; Medici 2010; Centoducatte et al. 2011). In our study area, a landscape composed basically of agriculture, eucalyptus forest, pasture, and secondary patches of Tabuleiro Forest, we identified footprints of the same individuals in at least two sites, from 1,110 to 4,494 meters apart. This result indicates that the landscape matrix in the RPPNRA area provides a certain level of 
269 functional connectivity that allow tapirs to mediate, considerably, the gene flow of many plant 270 species since they have a key role in the dispersion of many seeds (Tobler et al. 2009; Bueno et

271 al. 2013; O'Farrill et al. 2013; Giombini et al. 2016). This ability of tapir to travel among

272 heterogeneous habitats, dispersing seeds over distances is essential for plants that depend on long 273 dispersion to survive (Giombini et al. 2016).

$274 \quad$ FIT offers several substantial benefits over other monitoring methods, especially those 275 that are invasive to the study species (Alibhai et al. 2017). First, footprints of tapirs are easy to 276 find and very abundant. With appropriate weather conditions and substrates, and a moderate 277 sampling effort, footprints can be used effectively for censusing tapir populations. The RPPNRA 278 and its surroundings have more than 70 dirt roads, and all the roads used for this study (a total of 279 17) were visited by lowland tapirs at least once. Most of these unpaved roads have a good 280 substrate for footprints and trails (e.g., sand or clay substrate). They are located in different parts 281 of the studied area, covering different habitats, and footprint trails found were mostly long and 282 well defined. Also, it is likely that tapirs use dirt roads more frequently than off roads (e.g. Di 283 Bitetti et al. 2014). In our study area, footprints of tapir are more visible and frequent in those 284 unpaved roads than in other areas inside the forest, such as game trails. To find a footprint or a 285 long trail of footprints in the forest is a difficult task, especially because of the great amount of 286 litter that cover the forest floor. Second, an invasive method (i.e. immobilization and capture) carries a small risk of 288 individual mortality, and it is possible that immobilization itself may negatively impact on 289 female fertility (Alibhai et al. 2001). In addition, instrumented animals may exhibit changed 290 behavior that is not representative of the population as a whole, and therefore poses questions 291 about resulting data reliability (Jewell \& Alibhai 2013; Jewell 2013). Third, a systematic FIT 
292 survey can be carried out in a relatively short period of time depending on personnel and 293 resources. Fourth, FIT projects can employ local trackers' expertise to locate tapirs and other 294 species' footprints, supporting the local people and their valuable traditional knowledge. Lastly, 295 FIT can be used alongside camera-trapping or line transects as a powerful addition to the 296 monitoring toolbox. An additional finding was the significant relationship between the numbers 297 of trails and the estimated uniquely identified individuals of tapir that suggests that this could be 298 used as an effective method for estimating tapir numbers by simply counting the number of 299 trails. However, we believe that this needs to be validated in different study sites to include 300 detection probabilities before it is employed as a useful index for tapir censusing as it is likely to 301 be influenced by sampling procedure.

\section{Conclusions}

This is the first census survey attempt using footprints for the Tabuleiros Forest, and we 305 will continue to apply the FIT method to census populations and individuals over time in the RPPNRA and surrounding areas. We hope that this will form the basis of a long-term study that we can replicate in nearby sites to estimate the species population, and determine its status and viability in the Linhares-Sooretama forest complex region.

The FIT software can be made available free of charge (www.wildtrack.org), and sits as an add-in to JMP statistical analysis software which is available commercially (www.jmp.com).

311 We help non-profits and other groups with demonstrable need to apply for a Friends of JMP free 312 annual license. We offer in-situ FIT training workshops for users on request and usually hosted 313 in conjunction with a local partner. 
315 conserve tapirs. This technique is able to rapidly provide data on the numbers and distribution of 316 a key seed-disperser species, from footprints alone. A non-invasive and low-cost method, like

317 FIT, is essential to collect data on populations of threatened species, and provide those data to

318 managers of protected areas. Our surveys within a heterogeneous landscape, such as the

319 RPPNRA, with the identification of a minimum of 29 tapir individuals, confirms the

320 conservation value of this area as a stronghold for populations of Tapirus terrestris.

321

322 Acknowledgements

323 The authors would like to acknowledge the collaboration of Dr. Patrícia Medici, Dr. Stuart

324 Pimm, Mr. Diego Edon, B.Sc Paula Modenesi Ferreira and B.Sc. Amabili Falqueto Mistura. The 325 authors also would like to thank Fazenda Cupido \& Refúgio and the JMP division (jmp.com) of 326 SAS (sas.com) USA for their generous support.

327

328

References

329

330

331

332

333

334

335

336

337

Alibhai SK, Jewell ZC, Towindo SS. 2001. Effects of immobilization on fertility in female black rhino (Diceros bicornis). Journal of Zoology 253:333-345. DOI: $10.1017 / \mathrm{S} 0952836901000309$.

Alibhai SK, Jewell ZC, Law PR. 2008. A footprint technique to identify white rhino Ceratotherium simium at individual and species levels. Endangered Species Research 4:205-218. DOI: doi.org/10.3354/esr00067.

Alibhai SK, Jewell ZC, Evans J. 2017. The challenge of monitoring elusive large carnivores: An accurate and cost-effective tool to identify and sex pumas (Puma concolor) from footprints. PLoS ONE 12:e0172065. DOI: 10.1371/journal.pone.0172065. 
338 Almeida-Neto M, Campassi F, Galetti M, Jordano P, Oliveira-Filho A. 2008. Vertebrate

339 dispersal syndromes along the Atlantic forest: broad-scale patterns and macroecological

340

341 correlates. Global Ecology and Biogeography 17:503-513. DOI: 10.1111/j.1466-

8238.2008.00386.x.

342 Ballenger L, Myers P. 2001. Tapiridae. Available at http://animaldiversity.org/accounts/Tapiridae/(accessed 29 January 2017).

344 Boissier O, Bouiges A, Mendoza I, Feer F, Forget PM. 2014. Rapid assessment of seed removal and frugivore activity as a tool for monitoring the health status of Tropical Forests. Biotropica 46:633-641. DOI: 10.1111/btp.12134.

347 348 349

Bueno RS, Guevara R, Ribeiro MC, Culot L, Bufalo FS, Galetti M. 2013. Functional redundancy and complementarities of seed dispersal by the last neotropical megafrugivores. PLoS ONE 8:e56252. DOI: 10.1371/journal.pone.0056252.

Cadastro Nacional de Unidades de Conservação. 2015. Unidades de Conservação do Brasil [map]. Ministério do Meio Ambiente, 1:5.000 a 1:100.000. Brasília: Ministério do Meio Ambiente. Available at http://mapas.mma.gov.br/i3geo/datadownload.htm (accessed 18 December 2016).

Carbal-Borges JP, Godínez-Gómez O, Mendonza E. 2014. Density, abundance and activity patterns of the endangered Tapirus bairdii in one of its last strongholds in southern Mexico. Tropical Conservation Science 7:100-114. DOI: doi.org/10.1177/194008291400700102.

Centoducatte LDA, Moreira DO, Seibert JB, Gondim MFN, Acosta ICL, Gatti A. 2011. Tapirus terrestris occurrence in a landscape mosaic of Atlantic Forest and eucalyptus monoculture in southeast Brazil. Tapir Conservation 20/1 \& 2:16-19. 
361 Chiarello AG. 2000a. Density and population size of mammals in remnants of Brazilian Atlantic 362 forest. Conservation Biology 14:1649-1657. DOI: 10.1111/j.1523-1739.2000.99071.x.

363 Chiarello AG. 2000b. Influência da caça ilegal sobre mamíferos e aves das matas de tabuleiro do 364 norte do Espírito Santo. Boletim do Museu de Biologia Professor Mello Leitão (NSér) 11/12:229-247.

366 367 368

369

370

371 372 373 374 375 376 377 378 379 380 381 382 383

Conservação Internacional do Brasil, Fundação SOS Mata Atlântica, Fundação Biodiversitas, Instituto de Pesquisas Ecológicas, Secretaria do Meio Ambiente do Estado de São Paulo, Instituto Estadual de Florestas-MG. 2000. Avaliação e Ações Prioritárias para a Conservação da Biodiversidade da Mata Atlântica e Campos Sulinos. Brasília: MMA/SBF.

Cruz P, Paviolo A, Bó RF, Thompson JJ, Di Bitetti MS. 2014. Daily activity patterns and habitat use of the lowland tapir (Tapirus terrestris) in the Atlantic Forest. Mammalian Biology Zeitschrift für Säugetierkunde 79:376-383. DOI: dx.doi.org/10.1016/j.mambio.2014.06.003.

Di Bitetti MS, Paviolo A, De Angelo C. 2014. Camera trap photographic rates on roads vs. off roads: location does matter. Mastozoología neotropical 21: 37-46.

Dirzo R, Miranda A. 1991. Altered patterns of herbivory and diversity in the forest understory: A case study of possible consequences of contemporary defaunation. In: Price WP, Lewinsohn TM, Fernandes GW, Benson WW, eds. Plant-Animal Interactions: Evolutionary Ecology in Tropical and Temperate Regions. New York: John Wiley \& Sons, 273-287.

Eisenberg JF. 1981. The mammalian radiations: an analysis of trends in evolution, adaptation, and behavior. Chicago: University of Chicago Press. 
384 Elbroch M. 2003. Mammal tracks \& sign: a guide to North American species. Mechanicsburg: $385 \quad$ Stackpole Books.

386 Flesher K. 1999. Preliminary notes on the conservation status of Baird's tapir Tapirus bairdii in 387 north-eastern Honduras. Oryx 33:294-300. DOI: 10.1046/j.1365-3008.1999.00077.x.

388

389

390

391

392

393

394

395

396

397

398

399

400

401

402

403

404

405

406

Rica. Biotropica 34:423-437. DOI: 10.1111/j.1744-7429.2002.tb00556.x.

Fragoso JM. 1987. The habitat preferences and social structure of tapirs. M.Sc. Dissertation, University of Toronto.

Galetti M, Keuroghlian A, Hanada L, Morato MI. 2001. Frugivory and seed dispersal by the lowland tapir (Tapirus terrestris) in southeast Brazil. Biotropica 33:723-726. DOI: 10.1111/j.1744-7429.2001.tb00232.x.

Galetti M, Giacomini HC, Bueno RS, Bernardo CSS, Marques RM, Bovendorp RS, Steffler CE, Rubim P, Gobbo SK, Donatti CI, Begotti RA, Meirelles F, Nobre RA, Chiarello AG, Peres CA. 2009. Priority areas for the conservation of Atlantic forest large mammals. Biological Conservation 142:1229-1241. DOI: dx.doi.org/10.1016/j.biocon.2009.01.023

Gatti A, Brito D, Mendes SL. 2011. How many lowland tapirs (Tapirus terrestris) are needed in Atlantic Forest fragments to ensure long-term persistence? Studies on Neotropical Fauna and Environment 46:77-84. DOI: 10.1080/01650521.2011.562086.

Giombini MI, Bravo SP, Tosto DS. 2016. The key role of the largest extant Neotropical frugivore (Tapirus terrestris) in promoting admixture of plant genotypes across the landscape. Biotropica. DOI: 10.1111/btp.12328.

Glanz WE. 1990. Neotropical mammal densities: How unusual is the community of Barro Colorado Island, Panama. In: Gentry AH, ed. Four Neotropical rainforests. New Haven: 
407

408

409

410

411

412

413

414

415

416

417

418

419

420

421

422

423

424

425

426

427

428

429

Yale University Press, 287-313.

Gu J, Alibhai SK, Jewell ZC, Jiang G, Ma J. 2014. Sex determination of Amur tigers (Panthera tigris altaica) from footprints in snow. Wildlife Society Bulletin 38:495-502.

Gusset M, Burgener N. 2005. Estimating larger carnivore numbers from track counts and measurements. African Journal of Ecology 43:320-324. DOI: 10.1111/j.13652028.2005.00581.x.

Instituto Brasileiro de Geografia e Estatística. 1987. Projeto RADAM. Folha SE 24 Rio Doce. Rio de Janeiro: IBGE.

Instituto Brasileiro de Geografia e Estatística. 2001. Limites estaduais do Brasil [map]. Departamento de cartografia, 1:2 500 000. Brasília: Instituto Brasileiro de Geografia e Estatística (IBGE). Available at http://mapas.mma.gov.br/i3geo/datadownload.htm (accessed 18 December 2016).

Instituto Brasileiro de Geografia e Estatística. 2005. Malha municipal digital do Brasil [map]. Diretoria de Geociências, 1:2.500.000. Brasília. Instituto Brasileiro de Geografia e Estatística (IBGE). Available at http://mapas.mma.gov.br/i3geo/datadownload.htm (accessed 18 December 2016).

Instituto Chico Mendes de Conservação da Biodiversidade. 2016. Sumário executivo do livro vermelho da fauna brasileira ameaçada de extinção. Brasília: Ministério do Meio Ambiente. Available at http://www.icmbio.gov.br/portal/images/stories/comunicacao/publicacoes/publicacoesdiversas/dcom_sumario_executivo_livro_vermelho_da_fauna brasileira_ameacada_de_e xtincao_2016.pdf (accessed 23 February 2018).

Jewell ZC, Alibhai SK. 2001. Censuring and monitoring black rhino (Diceros bicornis) using an 
objective (footprint) identification technique. Journal of Zoology 254:1-16.

431 Jewell ZC. 2013. Effect of monitoring technique on quality of conservation science.

432 Conservation Biology 27:501-508. DOI: 10.1111/cobi.12066.

433 Jewell ZC, Alibhai SK. 2013. Identifying endangered species from footprints. The International

434 Society for Optics and Photonics (SPIE) Newsroom:1-3. DOI:

$435 \quad 10.1117 / 2.1201212 .004636$.

436 Jewell ZC, Alibhai SK, Evans JW. 2014. Monitoring mountain lion using footprints: a robust 437 new technique. Wild Felid Monitor 7:26-27

438 Jewell ZC, Alibhai SK, Weise F, Munro S, Van Vuuren M, Van Vuuren R. 2016. Spotting 439 cheetahs: identifying individuals by their footprints. Journal of Visualized Experiments $440 \quad$ e54034. DOI: $10.3791 / 54034$.

441 Li BV, Alibhai SK, Jewell ZC, Li D, Zhang H. 2018. Using footprints to identify and sex giant pandas. Biological Conservation 218:83-90. DOI: doi.org/10.1016/j.biocon.2017.11.029.

Medici EP. 2010. Assessing the viability of lowland tapir populations in a fragmented landscape. D. Phil. Thesis, University of Kent.

445

446

447

448

449

450

451

452

Medici EP. 2011. Family Tapiridae (Tapirs). In: Wilson DE, Mittermeier RA, eds. Handbook of the mammals of the world: Hoofed mammals. Barcelona: Lynx Editions, 182-204.

Medici EP, Desbiez ALJ. 2012. Population viability analysis: using a modeling tool to assess the viability of tapir populations in fragmented landscapes. Integrative Zoology 7:356-372. DOI: $10.1111 / \mathrm{j} .1749-4877.2012 .00318 . x$.

Medici EP, Flesher K, Beisiegel BM, Keuroghlian A, Desbiez ALJ, Gatti A, Pontes ARM, Campos CB, Tófoli CF, Moraes Jr. EA, Azevedo FC, Pinho GM, Cordeiro JLP, Santos Júnior TS, Morais AA, Mangini PR, Rodrigues LF, Almeida LB. 2012. Avaliação do 
453

454

455

456

457

458

459

460

461

462

463

464

465

466

467

468

469

470

471

472

473

474

475

risco de extinção da anta brasileira Tapirus terrestris Linnaeus, 1758, no Brasil.

Biodiversidade Brasileira II:103-116.

Mejía-Correa S, Diaz-Martinez A, Molina R. 2014. Densidad y hábitos alimentarios de la danta Tapirus bairdii en el Parque Nacional Natural Los Katios, Colombia. Tapir Conservation $23: 16-23$.

Michalski F, Peres CA. 2007. Disturbance-mediated mammal persistence and abundance-area relationships in Amazonian Forest fragments. Conservation Biology 21:1626-1640. DOI: 10.1111/j.1523-1739.2007.00797.x.

Naranjo EJ, Cruz E. 1998. Ecología del tapir en la Reserva de la Biósfera La Sepultura. Acta Zoológica Mexicana 73:111-125.

Naranjo EJ, Bodmer RE. 2007. Source-sink systems and conservation of hunted ungulates in the Lacandon Forest, Mexico. Biological Conservation 138:412-420. DOI: dx.doi.org/10.1016/j.biocon.2007.05.010.

Naveda A, Thoisy B, Richard-Hansen C, Torres DA, Salas L, Wallance R, Chalukian SC, Bustos S. 2008. Tapirus terrestris. Available at dx.doi.org/10.2305/IUCN.UK.2008.RLTS.T21474A9285933.en (accessed 12 November 2015).

Noss AJ, Cuéllar RL, Barrientos J, Maffei L, Cuéllar E, Arispe R, Rúmiz D, Rivero K. 2003. A Camera trapping and radio telemetry study of lowland tapir (Tapirus terrestris) in Bolivian Dry Forest. Tapir Conservation 12:24-32.

O'Farrill G, Calmé S, Sengupta R, Gonzalez A. 2012. Effective dispersal of large seeds by Baird's tapir: a large-scale field experiment. Journal of Tropical Ecology 28:119-122. DOI: $10.1017 / \mathrm{S} 0266467411000599$. 
476 O'Farrill G, Galetti M, Campos-Arceiz A. 2013. Frugivory and seed dispersal by tapirs: an 477 insight on their ecological role. Integrative Zoology 8:4-17. DOI: 10.1111/j.1749$478 \quad$ 4877.2012.00316.x.

479 Oliveira-Santos LGR, Zucco CA, Antunes PC, Crawshaw Jr PG. 2010. Is it possible to 480 individually identify mammals with no natural markings using câmera-traps? A controlled case-study with lowland tapirs. Mammalian Biology 75:375-378.

482

483

484

485

486

487

488

489

490

491

492

493

494

495

496

497

498

Peres CA. 2000. Effects of subsistence hunting on vertebrate community structure in Amazonian forests. Conservation Biology 14:240-253. DOI: 10.1046/j.1523-1739.2000.98485.x.

Petridou M, Sgardelis S, Youlatos D. 2008. Greece: an attempt to identify individual brown bears from their footprints. International Bear News 17:16-17.

Pimm SL, Alibhai SK, Bergl R, Dehgan A, Giri C, Jewell ZC, Joppa L, Kays R, Loarie S. 2015. Emerging technologies to conserve biodiversity. Trends in Ecology \& Evolution 30:685696. DOI: 10.1016/j.tree.2015.08.008.

Ramírez JFM. 2013. Diversidade genética e estrutura populacional da anta (Tapirus terrestris) na serra do mar, São Paulo, Brasil. M.Sc. Dissertation, Universidade Estadual Paulista.

Rizzini CT. 1997. Tratado de fitogeografia do Brasil: aspectos ecológicos, sociológicos e florísticos. Rio de Janeiro: Âmbito Cultural.

Simpson GG. 1980. Splendid isolation: the curious history of South American mammals. Westford: Yale University.

Souza JC, Cunha VP, Markwith SH. 2015. Spatiotemporal variation in human-wildlife conflicts along highway BR-262 in the Brazilian Pantanal. Wetlands Ecology and Management 23:227-239. DOI: 10.1007/s11273-014-9372-4.

Tobler MW, Carrillo-Percastegui SE, Powell G. 2009. Habitat use, activity patterns and use of 

Ecology 25:261-270.

501 Tobler MW, Hibert F, Debeir L, Richard-Hansen C. 2014. Estimates of density and sustainable 502 harvest of the lowland tapir Tapirus terrestris in the Amazon of French Guiana using a 503 Bayesian spatially explicit capture-recapture model. Oryx 48:410-419. DOI: $504 \quad 10.1017 / \mathrm{S} 0030605312001652$.

505 Wallace R, Ayala G, Viscarra M. 2012. Lowland tapir (Tapirus terrestris) distribution, activity 506 patterns and relative abundance in the Greater Madidi-Tambopata Landscape. Integrative 507 Zoology 7:407-419. DOI: 10.1111/1749-4877.12010. 


\section{Table $\mathbf{1}$ (on next page)}

Approximate distances (in meters) between sampling sites.

Study area is located in the Private Natural Heritage Reserve Recanto das Antas and surroundings, Espírito Santo, Brazil. In bold are the smallest and farthest distances between two sites. See map in Fig. 1 for sites reference. 


\begin{tabular}{lrrrrrr}
\hline & A & B & C & D & E & F \\
\hline A & 0 & & & & & \\
B & $\mathbf{1 1 1 0}$ & 0 & & & & \\
C & 6130 & 4245 & 0 & & & \\
D & 2893 & 1837 & 3872 & 0 & & \\
E & 1567 & 2547 & $\mathbf{6 2 9 7}$ & 2370 & 0 & \\
F & 4494 & 3868 & 4203 & 1860 & 2058 & 0 \\
\hline
\end{tabular}




\section{Table 2 (on next page)}

Number of lowland tapirs identified in one or more sites using the Footprint Identification Technique (FIT).

Study area is located in the Private Natural Heritage Reserve Recanto das Antas and surroundings, Espírito Santo, Brazil. See map in Fig. 1 for sites reference. Estimates of numbers of lowland tapirs are for summed data. Pooled data are in parenthesis. 


\begin{tabular}{|c|c|c|c|c|c|}
\hline Location & $\begin{array}{c}\# \text { of } \\
\text { footprints }\end{array}$ & \# of trails & \# of subtrails & $\begin{array}{c}\text { \# of } \\
\text { footprints } \\
\text { per subtrail } \\
\end{array}$ & $\begin{array}{c}\text { Estimated \# } \\
\text { of tapirs }\end{array}$ \\
\hline A & 150 & 16 & 23 & $5-8$ & 12 \\
\hline B & 71 & 9 & 10 & $6-8$ & 6 \\
\hline $\mathrm{C}$ & 20 & 2 & 4 & 5 & 1 \\
\hline D & 20 & 2 & 4 & 5 & 1 \\
\hline $\mathrm{E}$ & 99 & 10 & 15 & $5-8$ & 8 \\
\hline $\mathrm{F}$ & 80 & 7 & 12 & $6-8$ & 7 \\
\hline $\begin{array}{l}\text { TOTAL } \\
\text { FOR } \\
\text { STUDY } \\
\text { SITE }\end{array}$ & 440 & 46 & 68 & $5-8$ & $35(29)$ \\
\hline $\mathrm{A}+\mathrm{B}$ & 221 & 25 & 33 & $5-8$ & $18(15)$ \\
\hline $\mathrm{A}+\mathrm{C}$ & 170 & 18 & 27 & $5-8$ & $13(13)$ \\
\hline$A+D$ & 170 & 18 & 27 & $5-8$ & $13(13)$ \\
\hline $\mathrm{A}+\mathrm{E}$ & 249 & 26 & 38 & $5-8$ & 20 (19) \\
\hline $\mathrm{A}+\mathrm{F}$ & 230 & 23 & 35 & $5-8$ & $19(18)$ \\
\hline $\mathrm{B}+\mathrm{C}$ & 91 & 11 & 14 & $5-8$ & $7(7)$ \\
\hline $\mathrm{B}+\mathrm{D}$ & 91 & 11 & 14 & $5-8$ & $7(7)$ \\
\hline $\mathrm{B}+\mathrm{E}$ & 170 & 19 & 25 & $5-8$ & $13(13)$ \\
\hline $\mathrm{B}+\mathrm{F}$ & 151 & 16 & 22 & $6-8$ & $13(10)$ \\
\hline $\mathrm{C}+\mathrm{D}$ & 40 & 4 & 8 & 5 & $2(2)$ \\
\hline $\mathrm{C}+\mathrm{E}$ & 119 & 12 & 19 & $5-8$ & $9(9)$ \\
\hline $\mathrm{C}+\mathrm{F}$ & 100 & 9 & 16 & $5-8$ & $8(8)$ \\
\hline $\mathrm{D}+\mathrm{E}$ & 119 & 12 & 19 & $5-8$ & $9(9)$ \\
\hline $\mathrm{D}+\mathrm{F}$ & 100 & 9 & 16 & $5-8$ & $8(8)$ \\
\hline $\mathrm{E}+\mathrm{F}$ & 179 & 17 & 27 & $5-8$ & $15(15)$ \\
\hline
\end{tabular}


Figure 1

Survey sites for lowland tapir footprints.

Location of the main survey sites (A-F) used for lowland tapir footprints survey in the Private Natural Heritage Reserve Recanto das Antas and surroundings, Espírito Santo, Brazil.

Cartographic base source: Protected areas - Cadastro Nacional de Unidades de Conservação (2015); Political boundaries - Instituto Brasileiro de Geografia e Estatística (2001; 2005).

Datum: WGS 1984. Coordinate system/projection: UTM $24 S$.

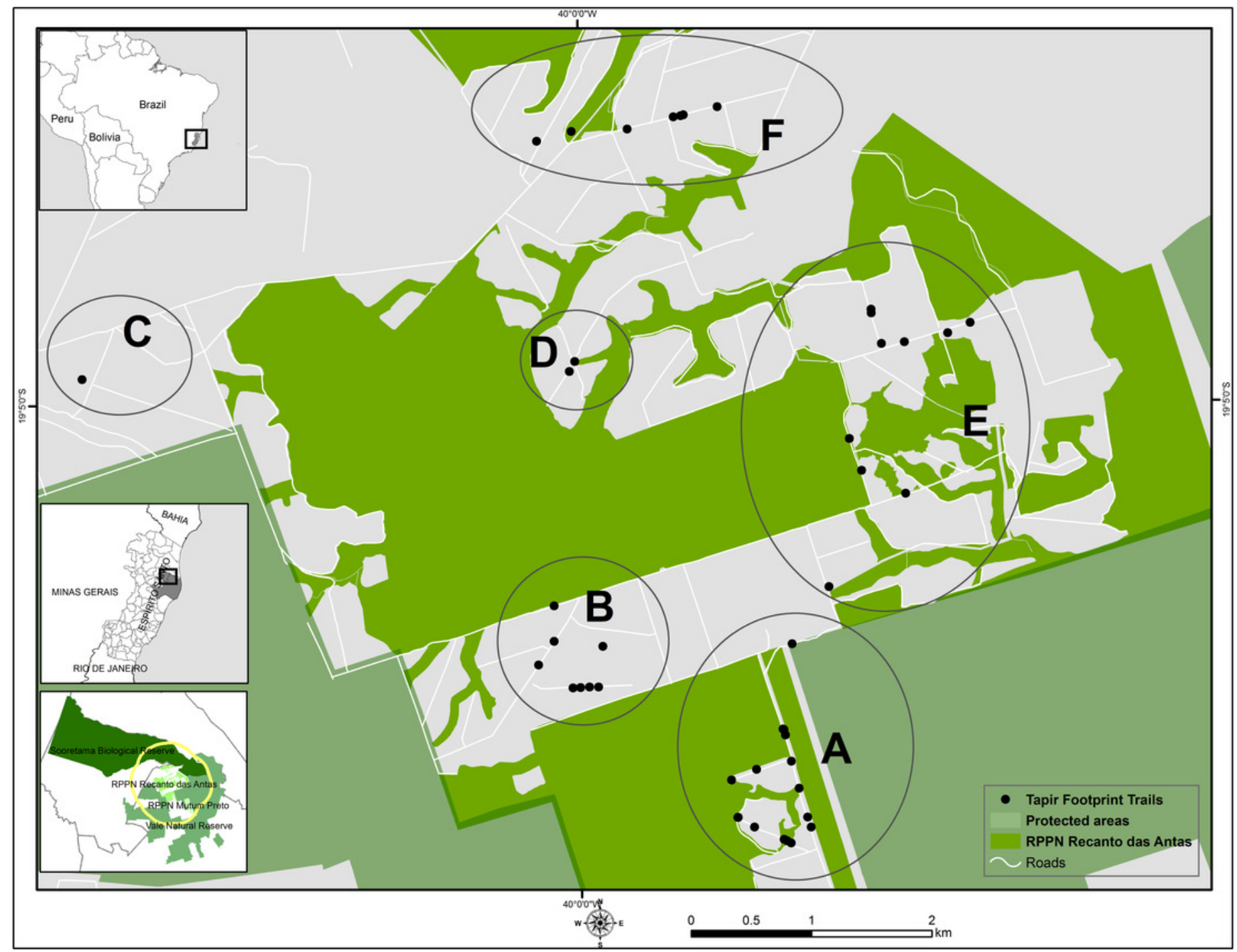




\section{Figure 2}

Lowland tapir trail and footprint.

(A) Trail of lowland tapir (Tapirus terrestris) along a dirt road. Photo credit: Danielle 0.

Moreira. (B) Lowland tapir left hind footprint photo collected during footprint surveys. Photo credit: Cristina J. da Cunha.
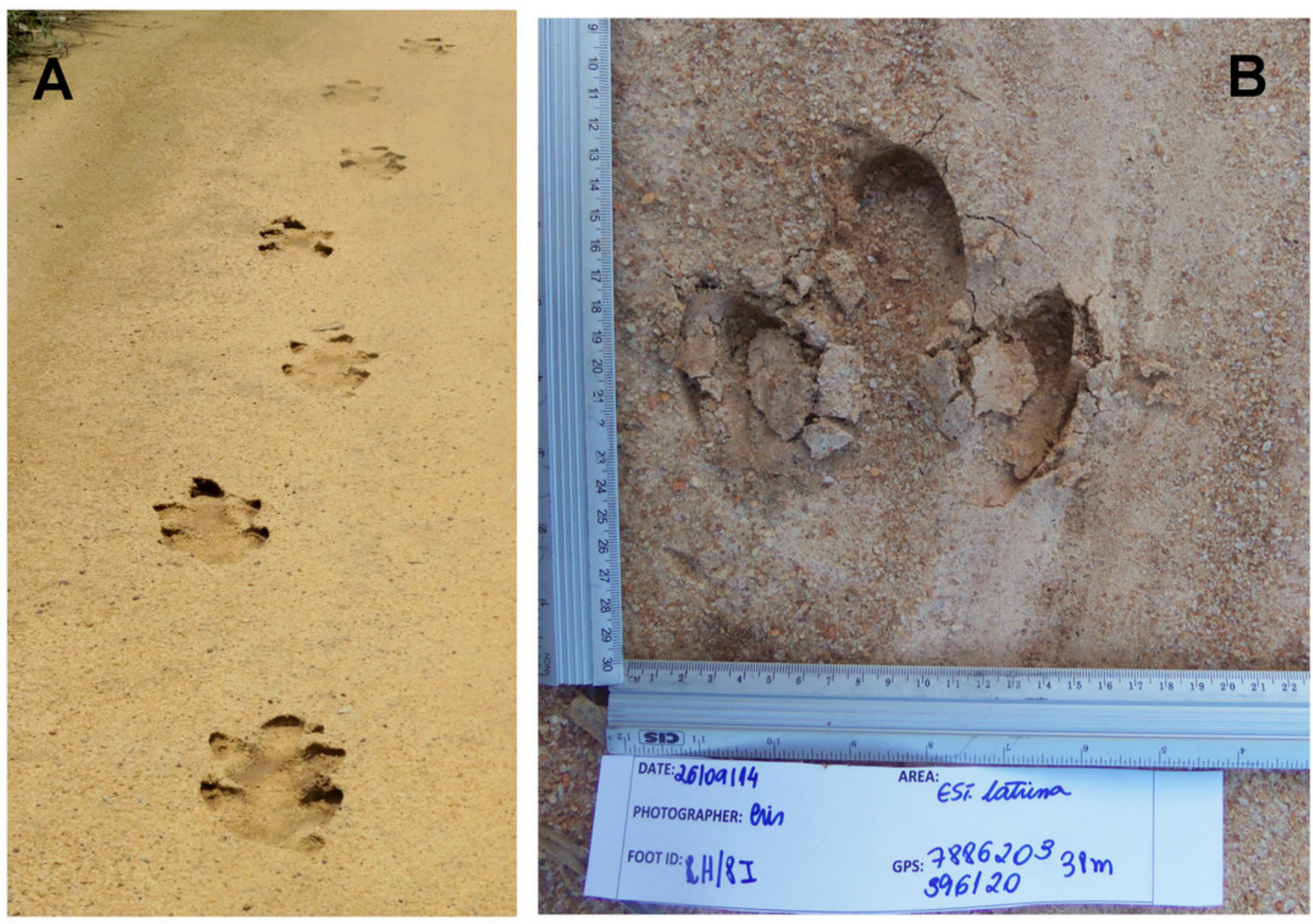


\section{Figure 3}

Footprint Identification Technique (FIT).

(A) Main menu window for lowland tapir in FIT. (B) Feature extraction window in FIT for lowland tapir. (C) Footprint image after processed using FIT script. Landmark points are in black and derived points in yellow. Image and photos credits: Danielle Moreira/ Andressa Gatti/ WildTrack.
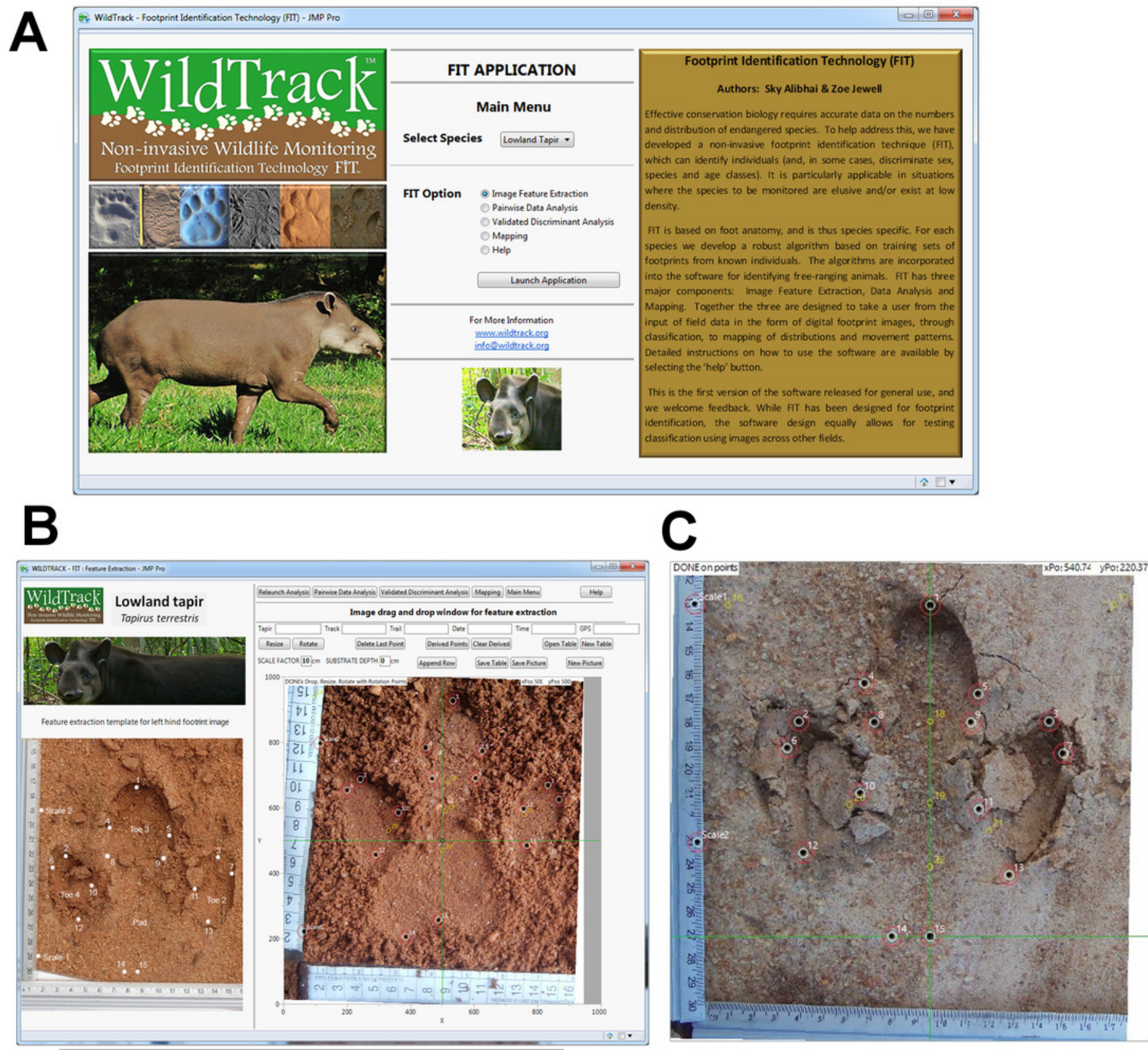


\section{Figure 4}

Dendrogram generated by FIT algorithm predicting the minimum number of lowland tapir (Tapirus terrestris) for the studied area.

(A) The first panel of the dendrogram shows 14 tapirs identified. (B) The second panel of the dendrogram shows more 15 tapirs identified. Surveys ranged from location $A$ to location $F$ (see Fig. 1 for sites references) in the Private Natural Heritage Reserve Recanto das Antas and surroundings, in Espírito Santo, Brazil. Each letter represents a location; a number represents a trail; a number and letter, a sub-trail; and the colors represent one individual.

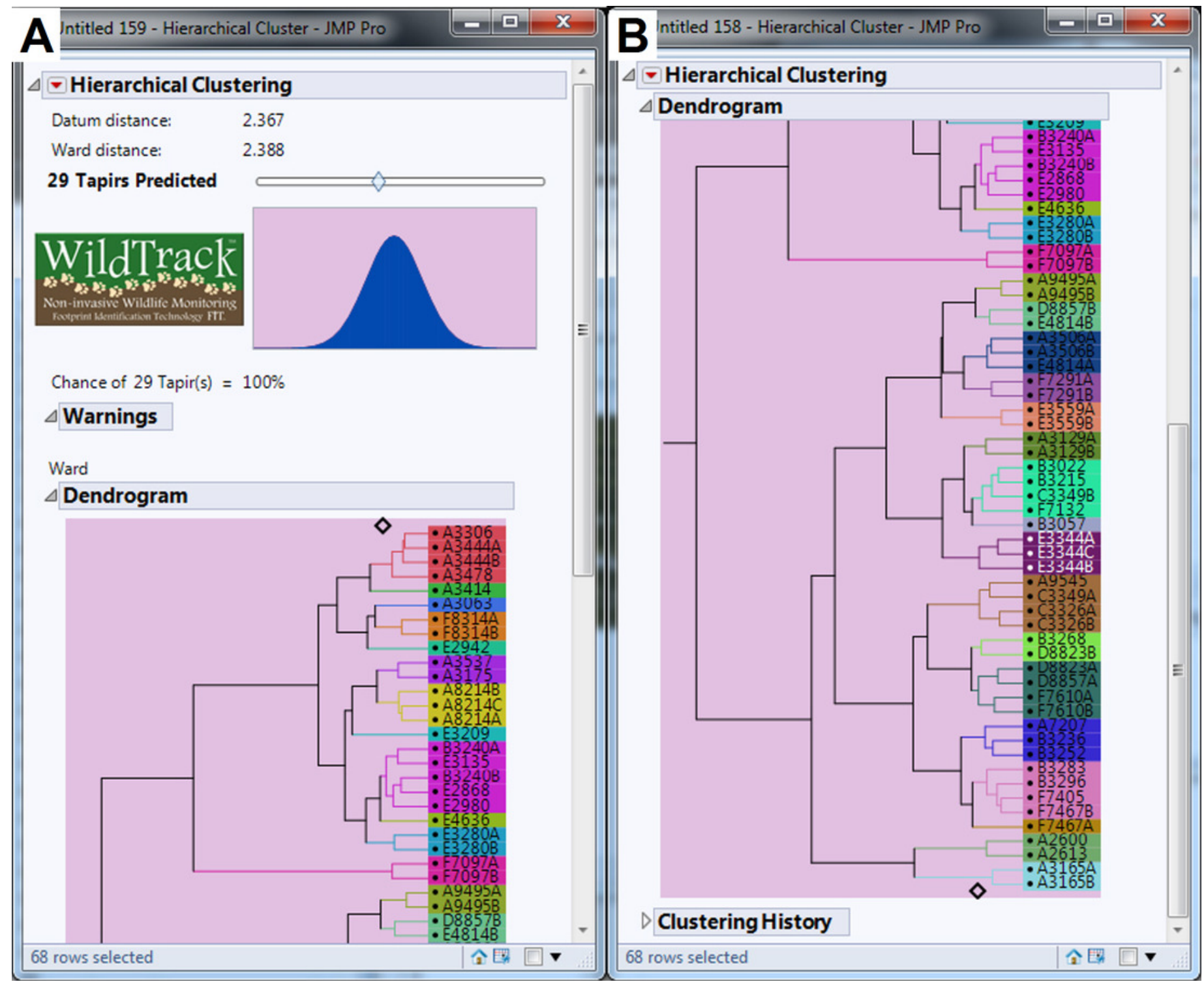


Figure 5

Relationship between numbers of trails and estimated number of unique individuals of lowland tapirs as determined by FIT in the study site.

The figures for numbers of trails are derived from the different locations ( $A$ to $F$ ) using separate locations and combinations of locations. Where locations were combined for the analysis, pooled estimates of tapir numbers were used.

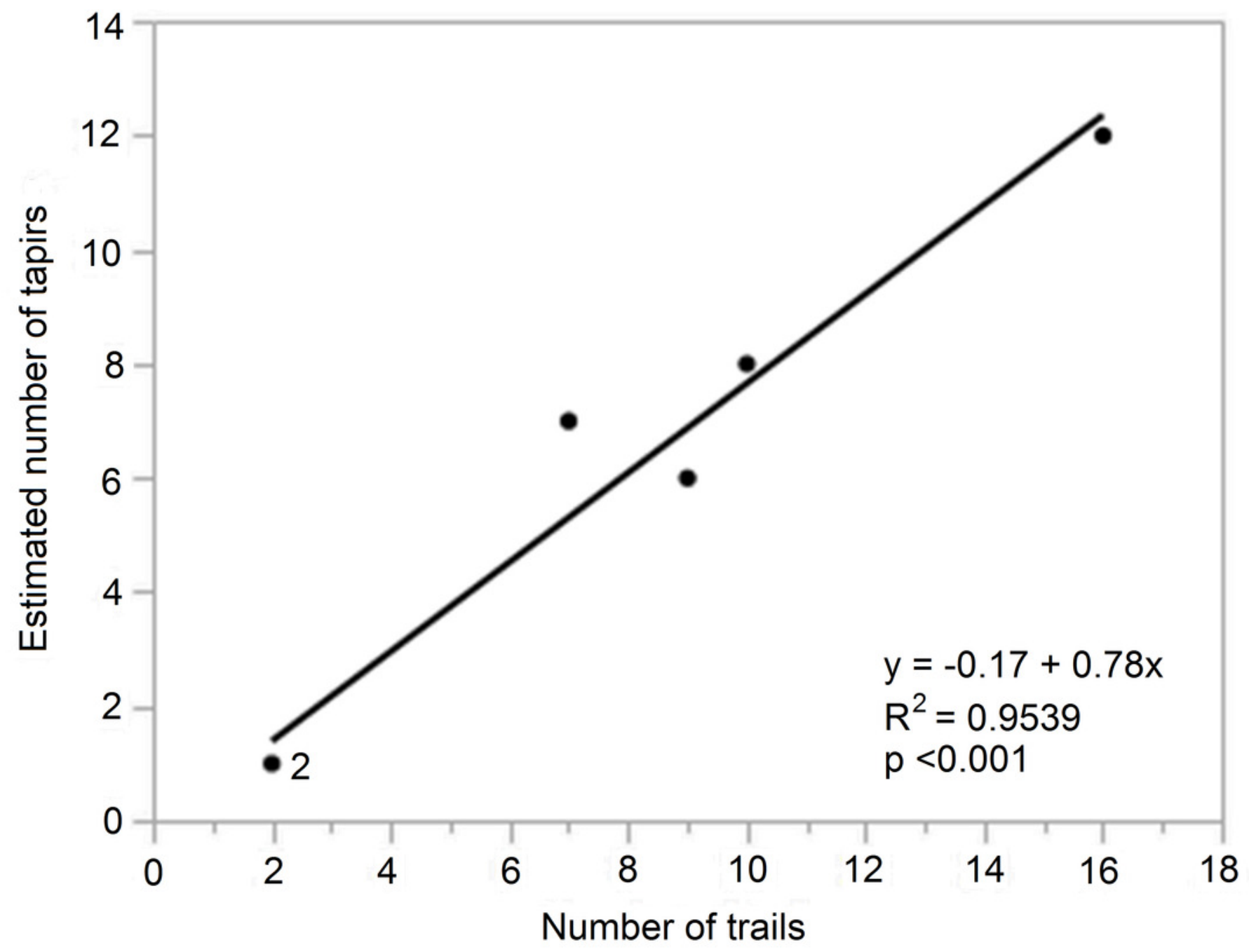

